\title{
Design and Implementation of a Thermal Load Reduction System for a Hyundai Sonata PHEV for Improved Range
}

\author{
Cory Kreutzer and John Rugh National Renewable Energy Laboratory
}

Matthew Scott Hyundai America Technical Center Inc.

James Gallagher Gentherm Inc

Citation: Kreutzer, C., Rugh, J., Scott, M., and Gallagher, J., “Design and Implementation of a Thermal Load Reduction System for a Hyundai Sonata PHEV for Improved Range," SAE Technical Paper 2018-01-1186, 2018, doi:10.4271/2018-01-1186.

\section{Abstract}

ncreased adoption of electric-drive vehicles requires overcoming hurdles including limited vehicle range. Vehicle cabin heating and cooling demand for occupant climate control requires energy from the main battery and has been shown to significantly degrade vehicle range. During peak cooling and heating conditions, climate control can require as much as or more energy than propulsion. As part of an ongoing project, the National Renewable Energy Laboratory and project partners Hyundai America Technical Center, Inc., Gentherm, Pittsburgh Glass Works, PPG Industries, Sekisui, $3 \mathrm{M}$, and Hanon Systems developed a thermal load reduction system to reduce the range penalty associated with electric vehicle climate control. Solar reflective paint, solar control glass, heated and cooled/ventilated seats, heated surfaces, and a heated windshield with door demisters were integrated into a Hyundai Sonata plug-in hybrid electric vehicle. Cold weather field-testing was conducted in Fairbanks, Alaska, and warm weather testing was conducted in Death Valley, California, to assess the system performance in comparison to the baseline production vehicle. In addition, environmental chamber testing at peak heating and cooling conditions was performed to assess the performance of the system in standardized conditions compared to the baseline. Experimental results are presented in this paper, providing quantitative data to automobile manufacturers on the impact of climate control thermal load reduction technologies to increase the advanced thermal technology adoption and market penetration of electric drive vehicles.

\section{Introduction}

ncreased market penetration of electric-drive vehicles (EDVs) requires overcoming several hurdles, including limited vehicle range and elevated cost in comparison to conventional vehicles. Climate control loads have a significant impact on range, reducing it by over $50 \%$ in both cooling and heating conditions [1]. To minimize the impact of climate control on EDV range, the National Renewable Energy Laboratory (NREL) partnered with Hyundai America Technical Center, Inc. (HATCI) and key industry partners Pittsburgh Glass Works, PPG Industries, Hanon Systems, Sekisui S-LEC America, Gentherm, and $3 \mathrm{M}$ to quantify the performance of thermal load reduction technologies on a Hyundai Sonata plug-in hybrid electric vehicle (PHEV). The overall goal of the project was to provide technology solutions that improve customer acceptance of EDVs and increase the penetration of these vehicles into the national fleet.

The project was divided into an individual technology development and assessment phase (Phase I) followed by a technology integration and performance evaluation phase (Phase II). The information generated in Phase II includes vehicle performance results of the thermal load reduction system obtained through standardized experimental testing performed at HATCI's test facilities.

Objectives of the project include:

- Increase grid-connected EDV range by $20 \%$ during operation of the climate control system by reducing thermal loads

- Implement a thermal load reduction system on a production vehicle and quantify performance of the system over the combined city/highway drive cycle at peak heating and cooling conditions

- Maintain occupant thermal comfort, verified through experimental evaluations.

\section{Approach and Results}

During Phase I, the project team focused on identification of candidate thermal load reduction technologies, determination 
of the design specifications for the technologies, implementation on a pre-production vehicle, and individual evaluation of the technologies [2]. In addition, analysis tools were constructed during Phase I, including a vehicle cabin thermal model, heating, ventilating and air conditioning (HVAC) system model, overall vehicle model, and national-level analysis process tools. These analysis tools were validated with Phase I experimental results and will be leveraged to provide an estimate of the impact of the thermal load reduction system on vehicle range on the national scale. Phase I concluded with a Go/No-Go decision point for integration of the candidate thermal load reduction technologies into the Phase II vehicle. Phase II focused on integration the thermal load reduction system into the vehicle and evaluating its performance experimentally through outdoor cold and hot weather testing in addition to environmental chamber evaluation.

The project leveraged collaboration between NREL and its project partners to complete all components of the project work plan. HATCI provided the vehicle platform, modeling data, and technology interfacing requirements for Phase I evaluation of technologies. HATCI also led Phase II of the project, including integration of technologies into the Hyundai vehicle platform and evaluation at HATCI facilities to characterize the performance of the vehicle. In addition to HATCI's contributions, the project relied on select tier one and tier two supplier research teams to develop, manufacture, aid in testing and analysis tasks, and provide general direction for the project. Pittsburgh Glass Works provided automotive glass manufacturing capabilities for the project in addition to advanced glass technologies for evaluation. Sekisui provided advanced materials and integration expertise for candidate thermal load reducing glass technologies, collaborating with Pittsburgh Glass Works for manufacturing. PPG Industries developed and provided baseline and solar reflective paint formulations for the Phase I and Phase II vehicles in addition to their thermal property characterization. Gentherm interfaced directly with both NREL and HATCI to develop and provide active seating, door glass defogging, and individual heated-surface technologies. Table 1 lists the technologies implemented and their operational status in the winter and summer. Finally, Hanon Systems performed experimental characterization of the vehicle's HVAC system and model inputs for construction and validation of the HVAC system model, in addition to providing expertise in HVAC system control.

TABLE 1 Operational status of the technologies in the winter and summer.

\begin{tabular}{|c|c|c|}
\hline Technology & $\begin{array}{l}\text { Operational } \\
\text { Status in Winter }\end{array}$ & $\begin{array}{l}\text { Operational Status } \\
\text { in Summer }\end{array}$ \\
\hline Solar reflective glass & $x$ & $x$ \\
\hline Heated windshield & $x$ & \\
\hline Solar reflective paint & $x$ & $x$ \\
\hline Heated surfaces & $x$ & \\
\hline Door demister & $x$ & \\
\hline Climate control seating & $x$ & $x$ \\
\hline
\end{tabular}

\section{Approach: Cold-Weather Field Evaluation}

Cold-weather field-testing was completed for two 2016 Hyundai Sonata PHEVs, one that was the baseline vehicle, and a second that contained the thermal load reduction system. The evaluations were performed in Fairbanks, Alaska, from February 23, 2017, through March 1, 2017. The test procedure consisted of manned transient and steady-state warmup tests, in addition to an unmanned defrost test. Ambient temperatures ranged from $-14^{\circ} \mathrm{C}$ to $-1{ }^{\circ} \mathrm{C}$ during the testing. The vehicles were operated at moderate speeds during the drive events due to adverse road conditions. The target speed was $80 \mathrm{kph}$ when road conditions allowed and a minimum of $50 \mathrm{kph}$ when conditions did not allow the higher speed. Most of the time the conditions were snowy and overcast. The route used was the "Fairbanks loop," which was a roughly 16-mile loop, and was repeated three times each test (Figure 1). Prior to the test, the vehicles were soaked in ambient conditions for a minimum of 4 hours and charged to $100 \%$ state of charge (SOC).

Just prior to the drive, the occupants soaked in the ambient conditions until a thermal sensation of cold (-3) was attained. Next, the occupants entered the vehicle and operated the defrost system until the vehicle windshields were clear and the vehicles were safe to drive (5 to 10 minutes). In addition to the standard defrost, the modified vehicle used the heated windshield. Thermal sensation votes were collected every 1 to 2 minutes during transient conditions and every 5 to 10 minutes during steady-state conditions. Transient drive segments were approximately 30 minutes in duration, followed by a 30-minute steady-state segment. A block diagram summary of the test process is shown in Figure 2, and an example of a vehicle during a test sequence is shown in Figure 3.

For the stationary defrost test, approximately $500 \mathrm{~mL}$ of distilled water was uniformly applied to the windshield and driver/passenger door glass prior to the start of the test. The baseline vehicle for the defrost test was operated in "Auto" mode with a display setpoint of $73^{\circ} \mathrm{F}$, while the modified vehicle used only the heated windshield and door demisters.

\section{FIGURE 1 Driving route on public roads in} Fairbanks, Alaska.

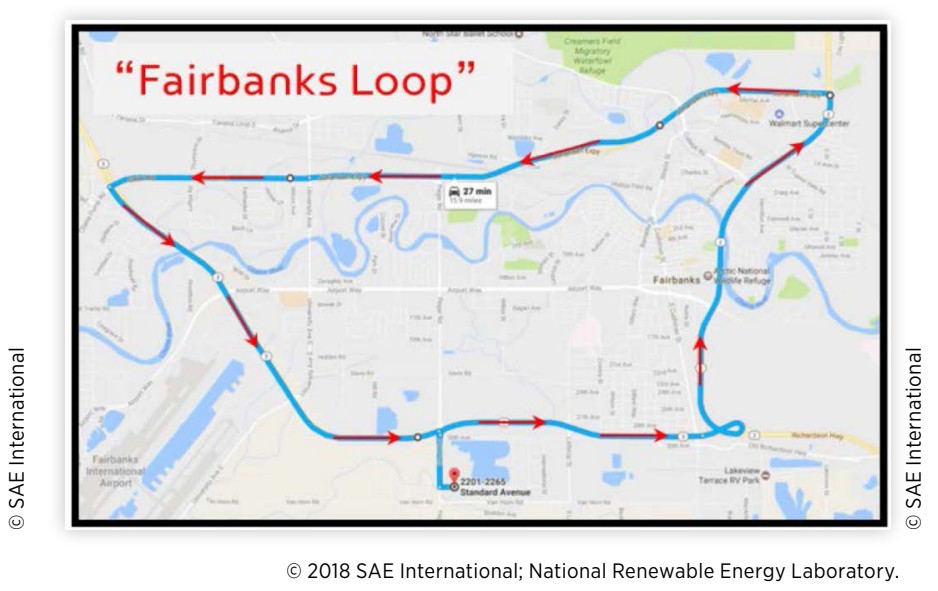


FIGURE 2 Test sequence for the cold-weather field evaluation - transient and steady-state drives and stationary defrost test.

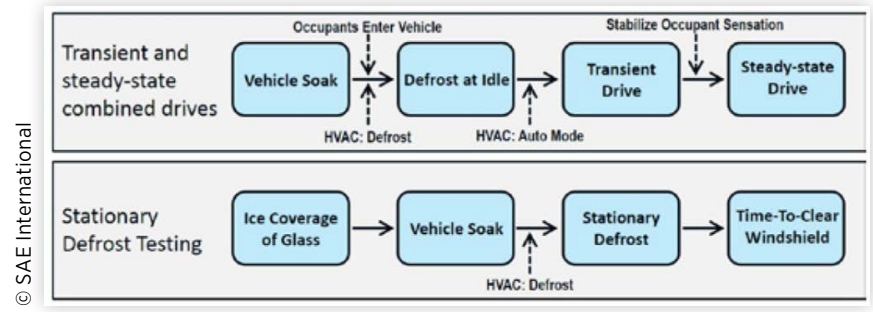

FIGURE 3 Hyundai Sonata PHEV under test in Fairbanks, Alaska. (photo credit: Cory Kreutzer, NREL)

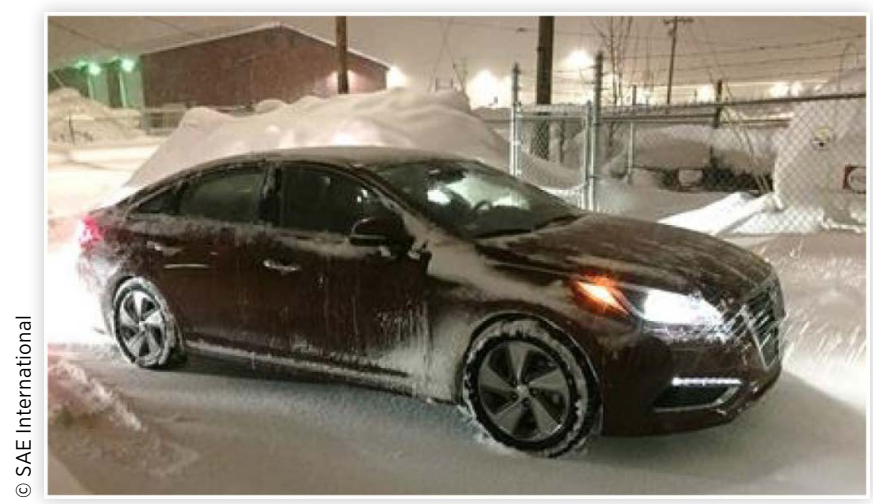

\section{Results: Cold-Weather Field Evaluation}

Cold-weather Phase II performance evaluation of the thermal load reduction system included the heated seats, heated windshield, door demisters, and heated surfaces. Table 2 shows the power consumed by the technologies for a typical 33-minute transient warm-up test.

The thermal load reduction system allowed for the modified vehicle automatic temperature control setpoint to be reduced significantly $\left(3{ }^{\circ} \mathrm{C}-5^{\circ} \mathrm{C}\right.$ on the HVAC control interface) while maintaining occupant comfort. Both transient and steady-state test segments showed significant improvements in engine off-time for the modified vehicle. The percent of time the engine was off for both vehicles during three drive events is shown in Figure 4. The system provided an average of $31.1 \%$ and $24.2 \%$ improvement in the engine-off time for

TABLE 2 Summary of the additional power and energy consumption for the technologies during a cold-weather field evaluation typical 33-minute drive.

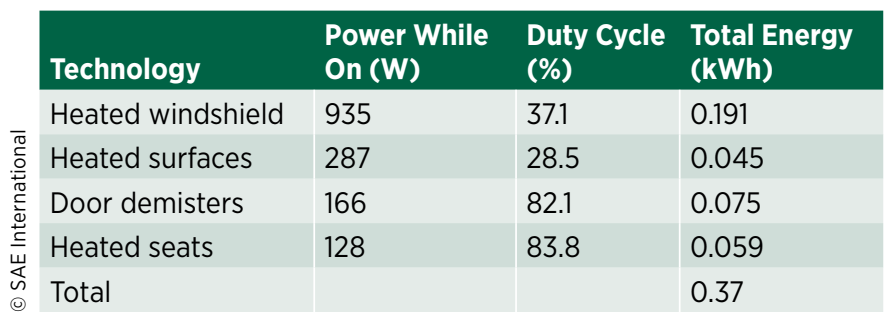

FIGURE 4 Percent of time engine was off during coldweather field transient and steady-state drives for both the baseline and thermal load reduction system vehicles.

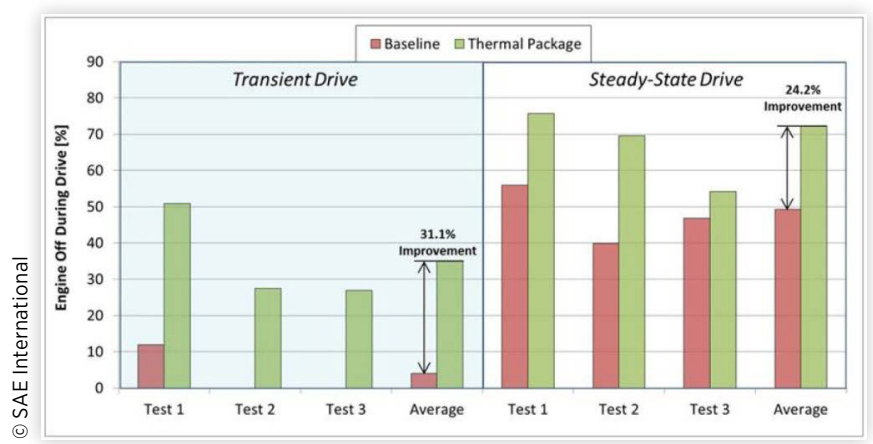

the transient and steady-state segments, respectively, in addition to a $48 \%$ reduction in the time for the occupants to achieve thermal comfort (15 min vs. $29 \mathrm{~min}$ in Figure 5).

In addition, the thermal load reduction system provided large improvements for the stationary defrost time and energy consumption. The results of the stationary defrost evaluation are shown in Figure 6. The thermal load reduction system completely cleared the iced windshield in 6 minutes, while the baseline system required 19 minutes. During this time,

FIGURE 5 Driver and passenger thermal sensation vs. time for February 27 field evaluation in Fairbanks, AK.

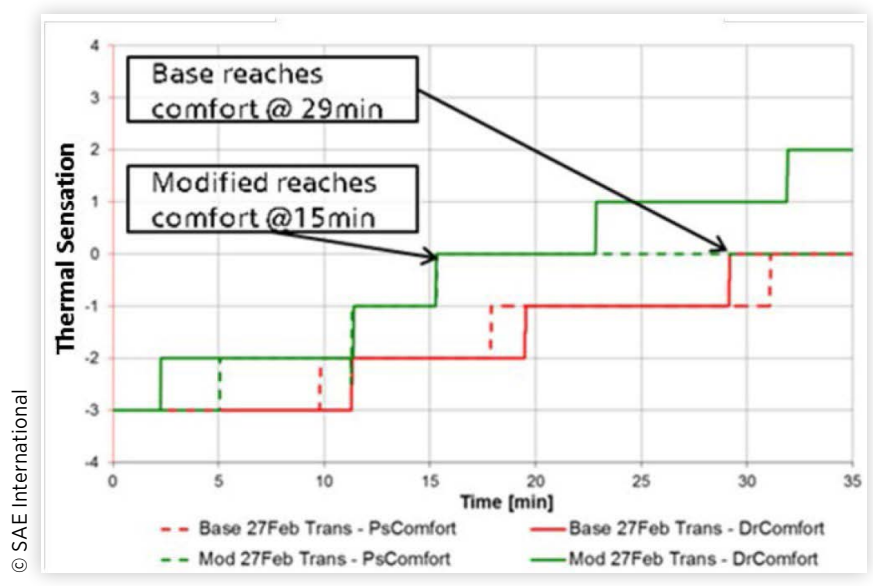

FIGURE 6 Results of stationary defrost cold-weather field evaluation for both the baseline and thermal load reduction. (photo credit: John Rugh, NREL)

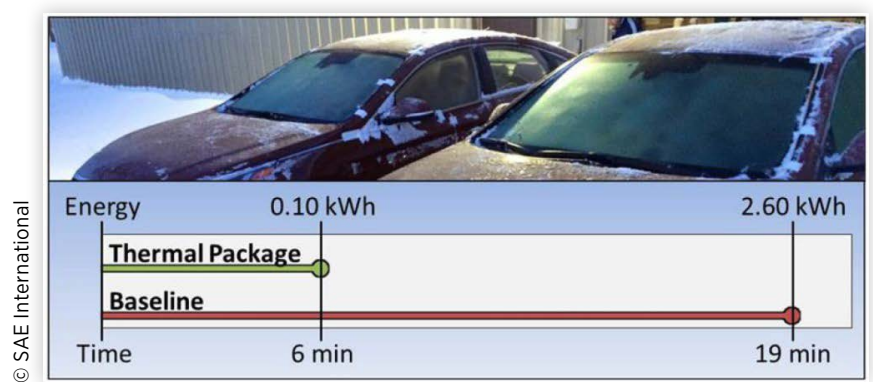


the thermal load reduction system used $0.1 \mathrm{kWh}$ of energy while the baseline system required $2.6 \mathrm{kWh}$ of energy. Finally, the cold weather field evaluations provided valuable control strategy information for system operation during the coldchamber evaluation. With the overall goal being to reduce power use while cooling or heating the occupant, Figure 7 shows a potential strategy for heating. The first step is to raise the windshield temperature using the windshield heater and then turn on the door demisters. This helps to increase the cabin temperature while minimizing the energy consumption from the main HVAC system. At this point, the HVAC setpoint is lowered to account for the use of the zonal technologies. The heated seats should be used continuously due to the low energy consumption and large positive impact on occupant comfort. On the other hand, the heated surfaces should be cycled to minimize energy consumption.

\section{Approach: Cold Chamber Evaluations}

Cold- and hot-weather chamber evaluations were performed in HATCI's environmental test chamber located at HATCI Headquarters in Superior Township, Michigan. The chamber evaluations used both the baseline vehicle and the vehicle equipped with the thermal load reduction system including the heated seats, heated windshield, door demisters, and heated surfaces. Both driver- and passenger-side technologies were operated to simulate two occupants. The cold-weather evaluation was performed using the U.S. Environmental Protection Agency's FTP-75 driving schedule with the chamber set at $-7{ }^{\circ} \mathrm{C}$ for the overnight soak and drive. The first part of the test procedure (referred to as Section 1 and equivalent to the FTP-72, or Urban Dynamometer Driving Schedule [UDDS]) consisted of a cold-start transient phase combined with a stabilized phase while Section 2 consisted of a hot-start transient phase (Figure 8). The baseline vehicle HVAC was set in "Auto" mode with a display setpoint of $73^{\circ} \mathrm{F}$ at the beginning of the drive, while the modified vehicle's HVAC setpoint was reduced below $73^{\circ} \mathrm{F}$ and adjusted during

\section{FIGURE 7 Potential cold weather HVAC control strategy} that captures the benefits of the thermal load reduction package to minimum energy consumption while maintaining occupant thermal comfort.

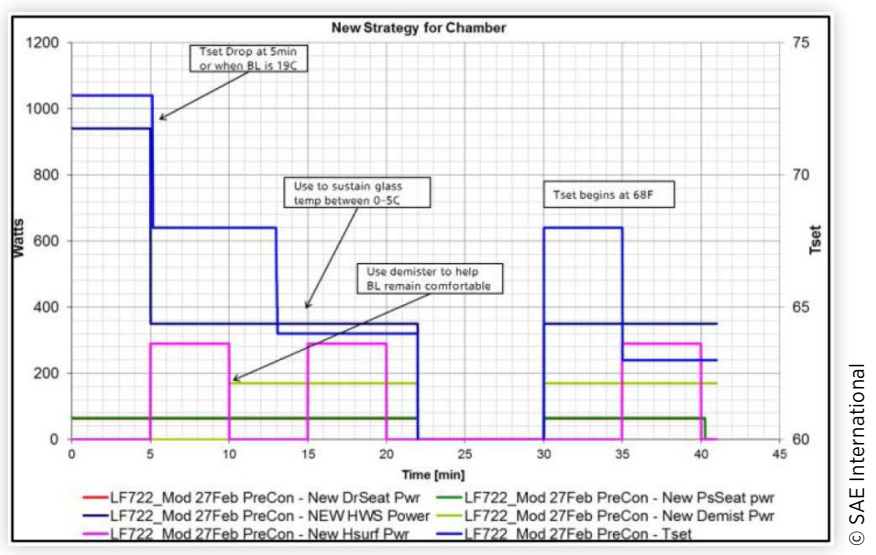

FIGURE 8 FTP-75 driving schedule used for the cold-chamber evaluations.

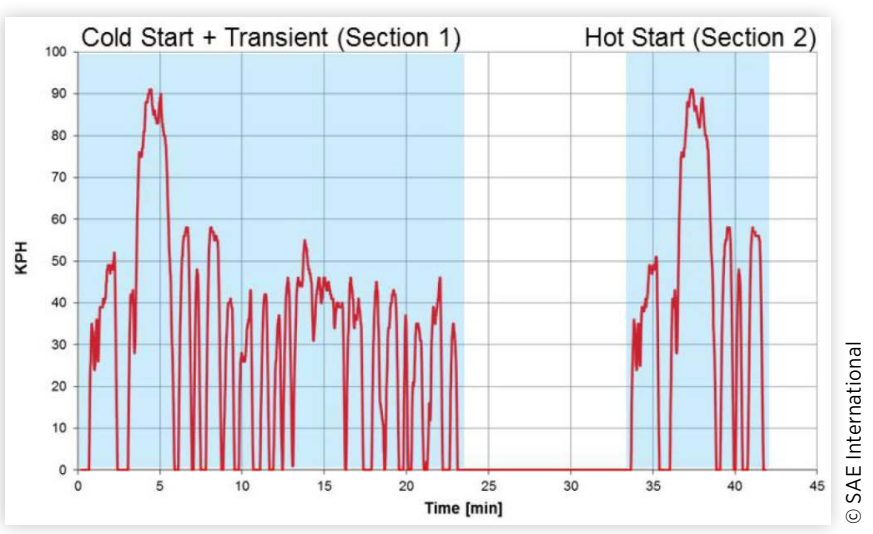

the test to attain occupant comfort equivalent to the baseline vehicle.

\section{Results: Cold Chamber Evaluation}

Cabin heating energy consumption for the cold-chamber evaluation for both the baseline and thermal load reduction system vehicles is provided in Figure 9. In Section 1, a large reduction in HVAC and positive temperature coefficient heater energy consumption was observed, but the total energy consumption was only $2.9 \%$ due to the energy to operate the technologies. Although energy reductions were modest in this section, occupants benefited by attaining thermal comfort 13 minutes sooner with the thermal package compared to the baseline. In Section 2, a 34.9\% reduction in energy was attained due to significant reductions in HVAC and positive temperature coefficient heating energy with only a small technology energy cost. Significant energy reduction for Section 2 of the test likely took place due to a combination of elevated coolant temperatures due to reduced heating demand, thermal storage of the advanced technologies, and fast response time of the technologies. The heating energy reduction for the thermal package compared to baseline was $12.9 \%$, equating to an $8.9 \%$ improvement in measured fuel economy for the PHEV for the FTP- 75 cycle at $-7^{\circ} \mathrm{C}$ (Sections 1 and 2).

FIGURE 9 Heating energy use results for the cold-chamber evaluation of the baseline and thermal load reduction vehicles $\left(-7{ }^{\circ} \mathrm{C}\right.$, FTP-75 drive cycle).

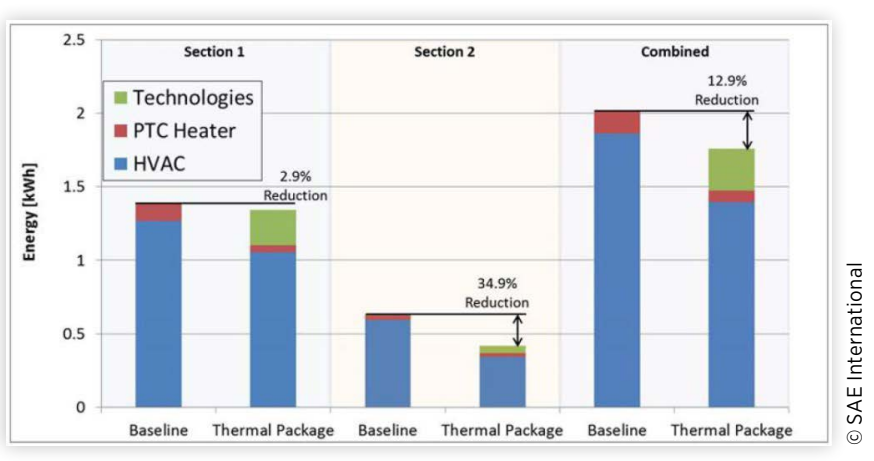

(c) 2018 SAE International; National Renewable Energy Laboratory. 
With the cabin setpoint reduced in the modified vehicle, less heat is requested from the HVAC system, which allows the coolant temperature to increase quicker than the base vehicle (Figure 10). At $10 \mathrm{~min}$ when the vehicles switch from defrost mode, the warmer coolant temperatures and operation of the technologies resulted in warmer breathlevel temperatures.

\section{Approach: Hot-Weather Field Evaluation}

Hot-weather field-testing was completed for the two vehicles at HATCI's California Proving Grounds and at Death Valley, California (Figure 11). Evaluations consisted of transient and steady-state driving cooldown tests and a 1-hour stationary idle cooldown test. Ambient temperatures ranged from $38^{\circ} \mathrm{C}$ to $50{ }^{\circ} \mathrm{C}$ during the test sequence. Transient drive segments were approximately 10 minutes in duration, followed by a 30-minute steady-state segment. For the 1-hour stationary idle cooldown test, both vehicles were set at "maximum cooling" mode and $100 \%$ recirculation. Prior to the drive, the vehicles were soaked in ambient conditions for a minimum of 4 hours and charged to $100 \%$ SOC. During the drive events,

FIGURE 10 Temperature setpoints, cabin breath air temperature, and thermal sensation/comfort for the cold chamber evaluation.

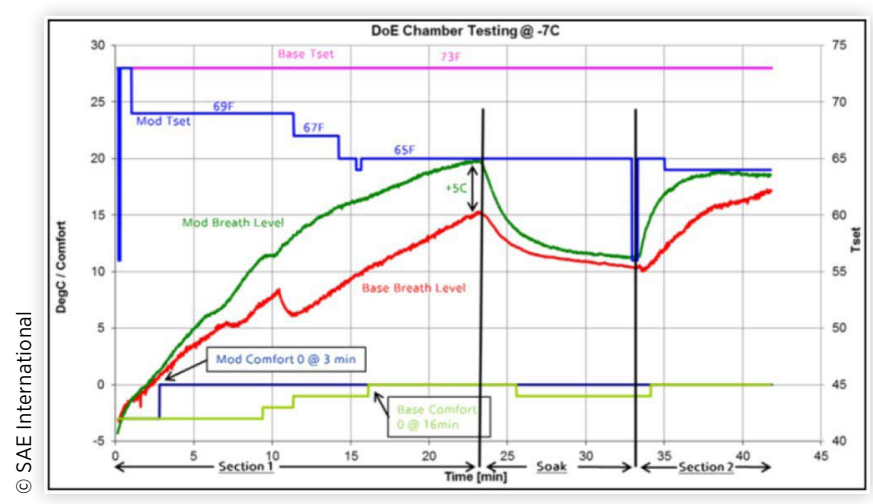

FIGURE 11 Hyundai Sonata PHEV under test in Death Valley, California. (photo credit: Dennis Schroeder, NREL, Image Gallery \# 46521)

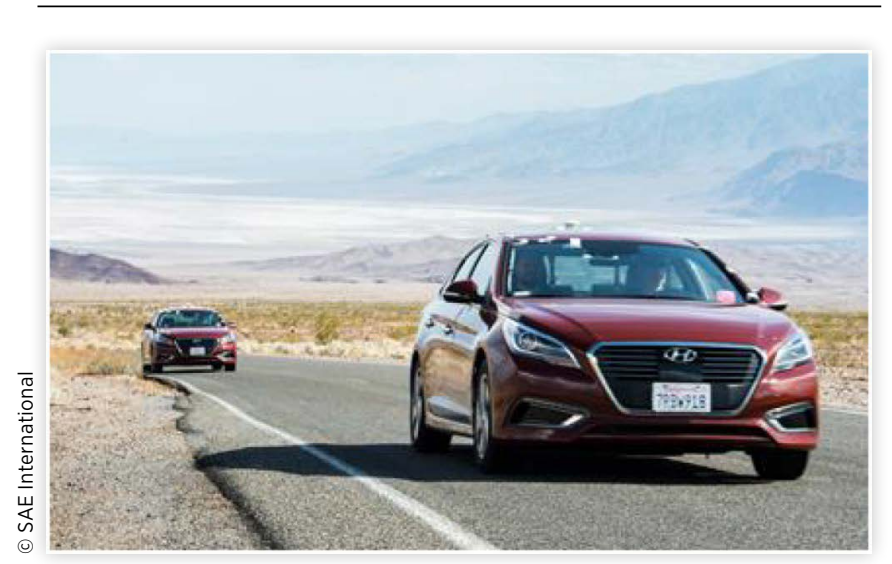

C) 2018 SAE International; National Renewable Energy Laboratory. the baseline vehicle HVAC was set in "Auto" mode with a display setpoint of $73^{\circ} \mathrm{F}$, while the modified vehicle was set in "Auto" mode with setpoint adjusted to attain occupant comfort. To determine real-world electric range, both vehicles were soaked, fully charged, and driven on the oval until the vehicles entered charge-sustaining mode (engines came on). The difference in distance covered before charge-sustaining mode is the change in electric range.

\section{Results: Hot-Weather Field Evaluation}

Hot-weather Phase II performance evaluation of the thermal load reduction system assessed the impact of ventilated/cooled seats, solar control glass, and solar reflective paint. These technologies reduced the soak temperatures of the modified vehicle and air-conditioning (A/C) energy as well as improved the time-to-comfort for the occupants.

Figure 12 shows the A/C compressor power for the modified vehicle is reduced before the baseline vehicle due to the lower thermal loads, and remains lower than the baseline as the cabin transitions to a steady-state thermal condition. Figure 13 shows the compressor power in the modified vehicle is lower than the baseline vehicle during the steady-state test. This is due in part to the ability to have a higher set point possible and still maintain comfort. The added power of the ventilated/cooled seats is also plotted in Figure 13. Accounting for this additional electrical load, there is still a net reduction in climate control power. For the drive events, an average reduction in climate control energy of $14.2 \%$ and $19.4 \%$ was measured for the transient and steadystate segments, respectively.

In addition, a drive evaluation was completed at moderate steady speeds with the vehicles locked in electric vehicle (EV) mode. Prior to the 27-minute mark when the baseline engine turned on, the SOC of the modified vehicle was higher than the baseline due to the reduced HVAC energy use (Figure 14). For the EV-only drive, A/C energy was reduced by $23.7 \%$ compared to the baseline, equating to an $11.4 \%$ improvement in EV range.

FIGURE 12 Baseline and modified vehicle A/C compressor power for a 20-minute transient cooldown on August 2, 2017 $\left(49^{\circ} \mathrm{C}, 850 \mathrm{~W} / \mathrm{m}^{2}\right)$.

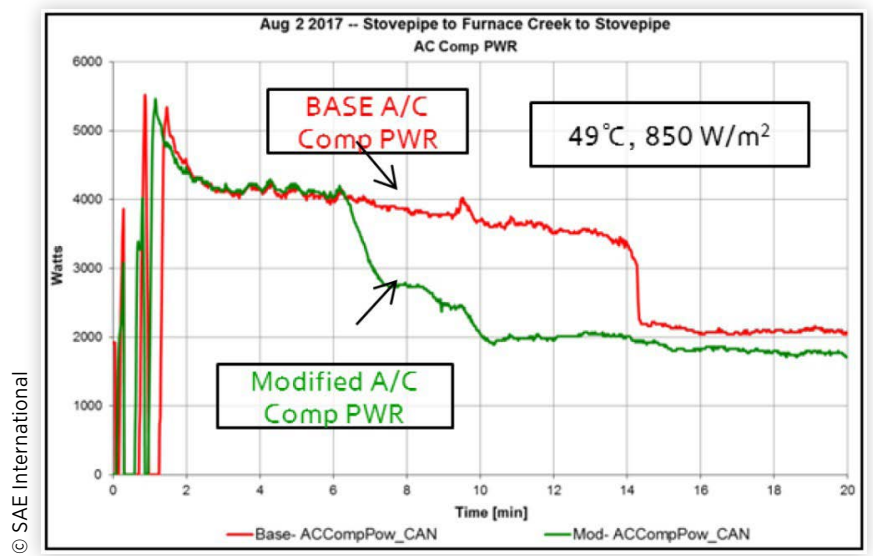


FIGURE 13 Steady-state baseline and modified vehicle A/C compressor power and seat power $\left(45^{\circ} \mathrm{C}, 970 \mathrm{~W} / \mathrm{m}^{2}\right)$.

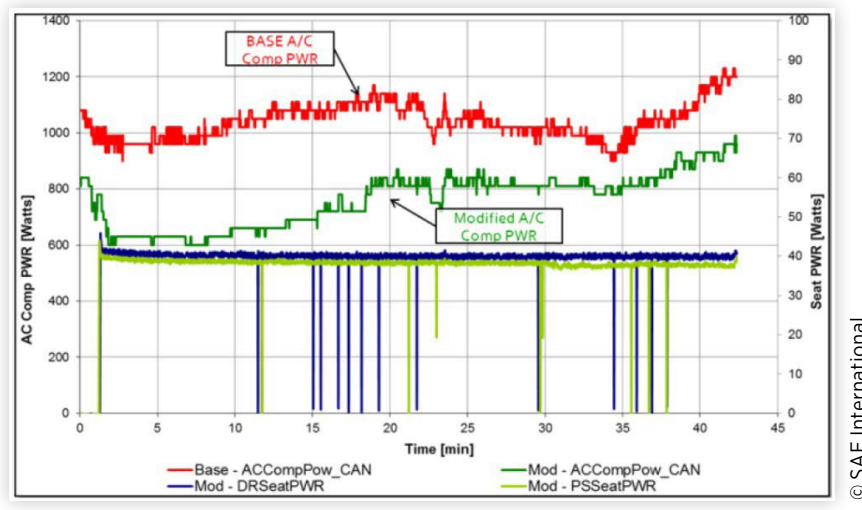

FIGURE 14 SOC, vehicle speed and engine rpm for the baseline and modified vehicles locked in $\mathrm{EV}$ mode $\left(38^{\circ} \mathrm{C}\right.$, $\left.1,000 \mathrm{~W} / \mathrm{m}^{2}\right)$.

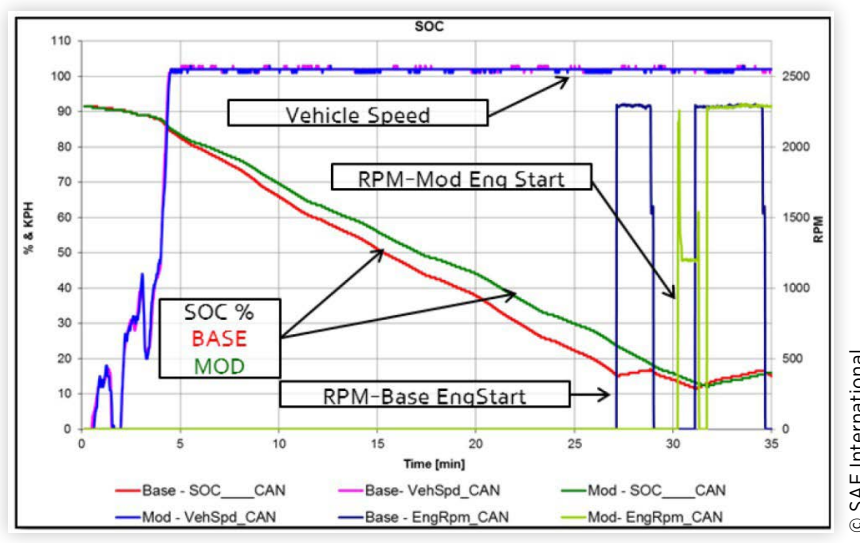

FIGURE 15 Average cabin breath air temperature for the baseline and modified vehicles locked in EV mode $\left(38^{\circ} \mathrm{C}\right.$, $\left.1,000 \mathrm{~W} / \mathrm{m}^{2}\right)$.

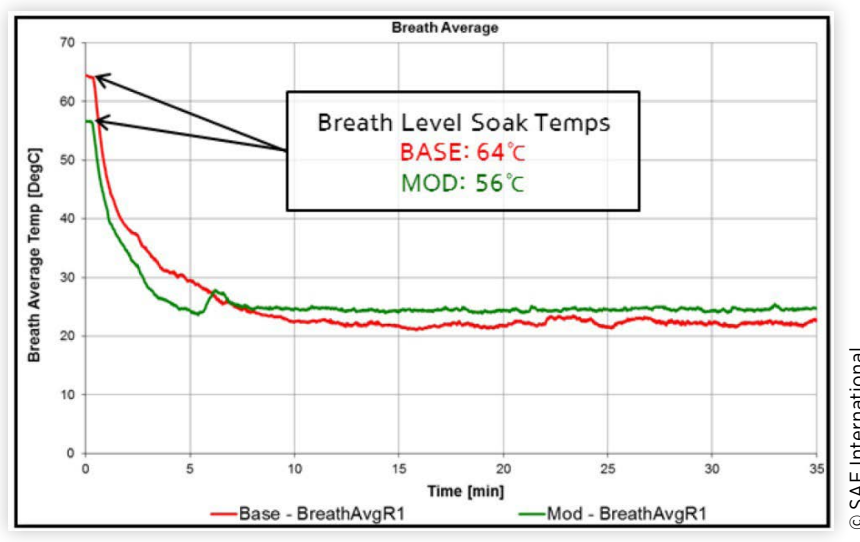

Throughout the test, the vehicle containing the thermal load reduction package was able to maintain the cabin breath level temperatures higher than the baseline vehicle. Figure 15 shows an $8{ }^{\circ} \mathrm{C}$ reduction in hot-soak breath air temperature at the beginning of the drive and $3{ }^{\circ} \mathrm{C}$ higher
FIGURE 16 Exterior roof temperature for the baseline and modified vehicles during the stationary max $\mathrm{A} / \mathrm{C}$ test $\left(43^{\circ} \mathrm{C}\right.$, $940 \mathrm{~W} / \mathrm{m}^{2}$.

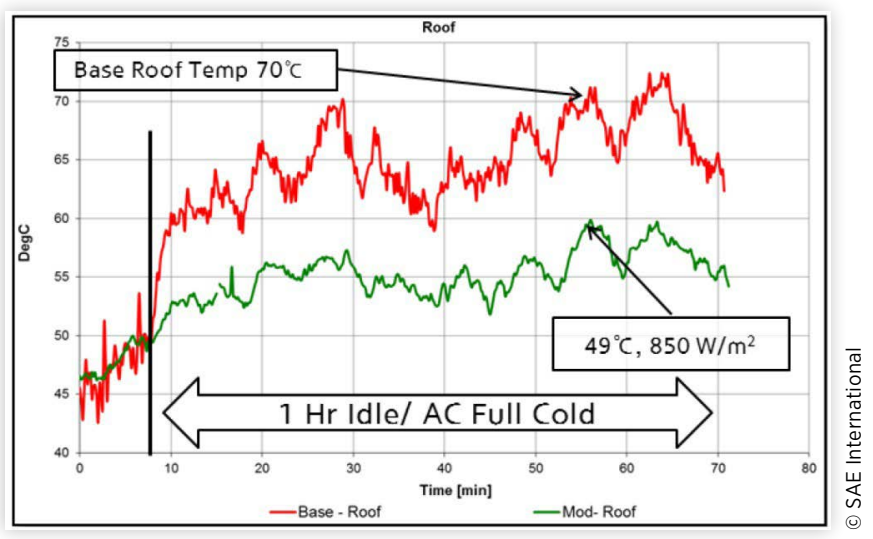

FIGURE 17 Interior glass temperature for the baseline and modified vehicles during the stationary max $\mathrm{A} / \mathrm{C}$ test $\left(43^{\circ} \mathrm{C}\right.$, $\left.940 \mathrm{~W} / \mathrm{m}^{2}\right)$.

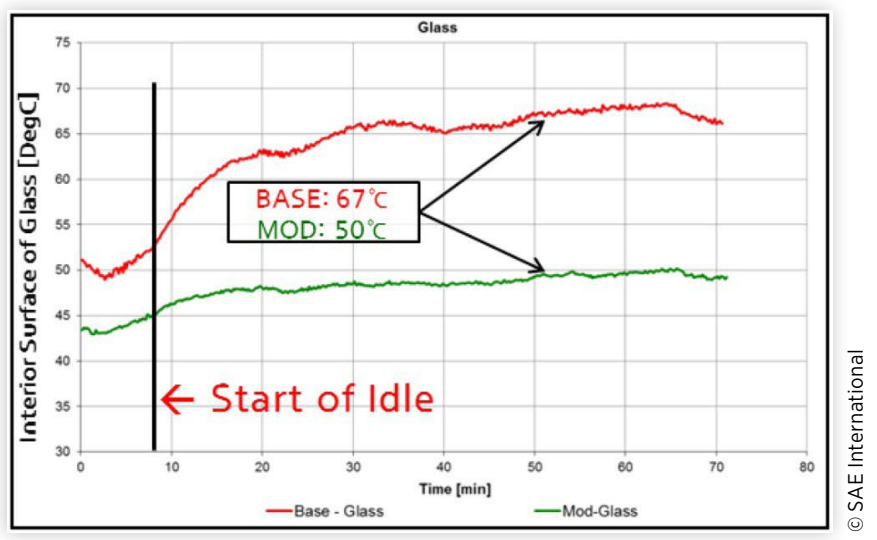

breath air temperature at steady state in the modified vehicle due to the high cabin setpoint. The higher cabin setpoint resulted in lower thermal loads and energy consumed by the A/C compressor. This is how the thermal package impacts vehicle performance. The thermal package creates a local environment around the occupant that allows a higher cabin temperature while the occupant remains comfortable.

During the stationary 1-hour idle max cooling test, the solar reflective paint reduced the exterior roof surface temperature an average of $10^{\circ} \mathrm{C}$ as shown in Figure 16 . This reduced the conductive heat transfer through the roof to the vehicle interior. Similarly, the solar control glass reduced both the glass temperature and cabin temperature for the modified vehicle. Figure 17 shows the solar control glass reduces the inside glass surface temperature $17^{\circ} \mathrm{C}$ compared to baseline. The reduced heat gain into the vehicle had a combined benefit of a $3.3{ }^{\circ} \mathrm{C}$ lower cabin breath air temperature and a $4.5 \% \mathrm{~A} / \mathrm{C}$ compressor energy usage reduction compared to the baseline vehicle during the stationary 1-hour idle max cooling test. 
FIGURE 18 AC17 driving schedule used for the hot-chamber evaluation.

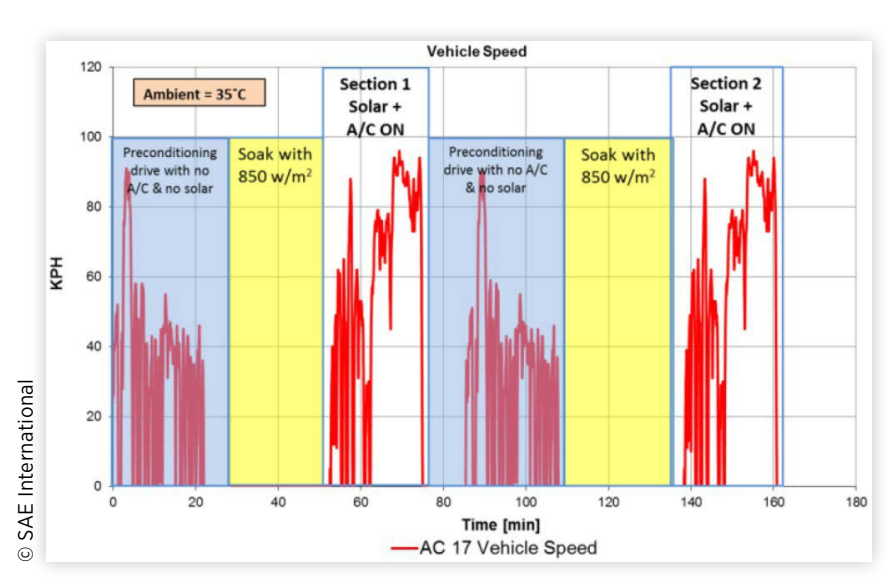

\section{Approach: Hot Chamber Evaluations}

The hot-weather evaluations of the two vehicles were performed using a modified AC17 test procedure shown in Figure 18. The test conditions were modified to represent more severe conditions seen in the United States than what the standard AC17 conditions specify. Prior to the test, the vehicles were soaked indoors at room temperature. Thereafter, the vehicles were placed in the chamber and the chamber temperature was held at $35^{\circ} \mathrm{C}$ with a humidity of $100 \mathrm{~g} / \mathrm{lb}$. for a 30 -minute soak. In addition, $850 \mathrm{~W} / \mathrm{m}^{2}$ of solar was applied to the vehicle using lamps during the hot solar soak, SC03, and Highway Fuel Economy (HWFET) test phases. The baseline vehicle HVAC was set in "Auto" mode with a display setpoint of $72{ }^{\circ} \mathrm{F}$ at the beginning of the drive, while the modified vehicle HVAC setpoint was increased above $72^{\circ} \mathrm{F}$ and adjusted during the test to attain occupant comfort equivalent to the baseline vehicle.

\section{Results: Hot Chamber Evaluation}

Figure 19 shows an example of the average cabin breath air temperature during the different segments of the test. The modified vehicle had a lower cabin breath air temperature during the soak and a higher cabin breath air temperature during the drive due to the higher HVAC setpoint. The energy needed to cool the passenger compartment for each section of the hot chamber evaluation for both the baseline and thermal load reduction system vehicles is shown in Figure 20. In Section 1, a 22.9\% reduction in energy was measured with the thermal package due to a reduction in thermal loads during the vehicle soak and drive events and accounting for the energy used by the ventilated/cooled seat. In Section 2, a $27.8 \%$ reduction in energy was attained using the technologies. Significant energy reduction for both sections of the test resulted from a reduction in the vehicle cabin air and component temperatures during the solar soak and reduced thermal loads during the drive due to the solar control glass and solar reflective paint. Another significant contributing factor to
FIGURE 19 Example cabin breath air temperature during the modified AC17 driving test used for the hot-chamber evaluations.

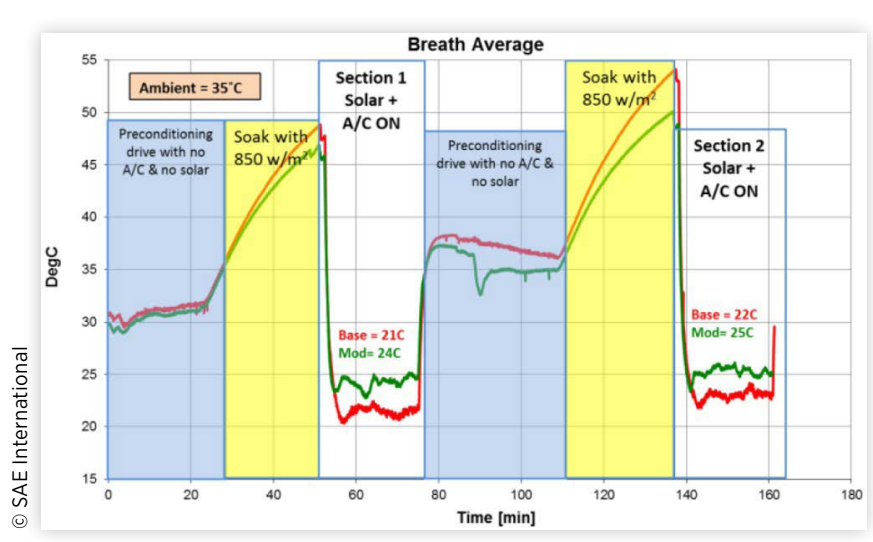

FIGURE 20 Cooling energy use results for the hot-chamber evaluation of the baseline and thermal load reduction vehicles ( $35^{\circ} \mathrm{C}, 850 \mathrm{~W} / \mathrm{m}^{2}, 100 \mathrm{~g} / \mathrm{lb} .$, AC17 drive cycle).

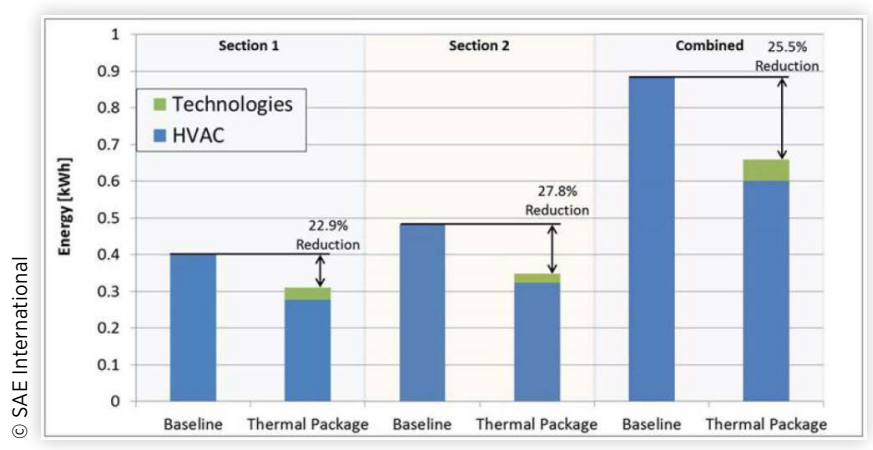

reducing energy consumption was that thermal comfort was attained with a higher cabin air temperature $\left(3^{\circ} \mathrm{C}\right)$ due to the operation of the ventilated /cooled seats. The cooling energy reduction for the thermal package compared to baseline was $25.5 \%$, equating to a $21.8 \%$ improvement in fuel economy for the PHEV over the modified AC17 drive cycle at $35^{\circ} \mathrm{C}$.

\section{Summary/Conclusions}

Environmental chamber and field evaluations were completed for the thermal load reduction system in Phase II of the project. Hyundai Sonata PHEVs equipped with baseline and thermal load reduction systems were evaluated at HATCI's chamber test facility in Superior Township, Michigan. Coldweather field evaluations were completed in Fairbanks, Alaska, while hot-weather field evaluations were completed in Death Valley, California. Cold-chamber and field evaluation of the modified Sonata PHEV included heated seats, heated windshield, door demisters, and heated surfaces. Cold-weather field testing provided an opportunity to develop a control strategy and demonstrate performance of the thermal load reduction system in real-world driving conditions. The cold-chamber evaluation demonstrated a $12.9 \%$ heating energy reduction 
TABLE 3 Summary of the energy and fuel savings measured during the hot and cold chamber evaluations.

\begin{tabular}{|c|c|c|}
\hline \multicolumn{3}{|c|}{ Overall Savings of Thermal Package } \\
\hline \multicolumn{3}{|l|}{ Chamber - Hot } \\
\hline & Climate Control Energy Use & $25.5 \%$ \\
\hline & Fuel Use * & $21.8 \%$ \\
\hline \multicolumn{3}{|l|}{ Chamber - Cold } \\
\hline & Climate Control Energy Use & $12.9 \%$ \\
\hline & Fuel Use * & $8.9 \%$ \\
\hline
\end{tabular}

* Chamber tests did not include full EPA certification tests. Data applicable for project test conditions.

with the thermal load reduction system from the baseline Sonata PHEV, equating to an $8.9 \%$ improvement in fuel economy. Hot-chamber and field evaluation of the modified Sonata PHEV included solar control glass, solar reflective paint, and cooled seats. Hot-weather field testing provided an opportunity to demonstrate the system performance using HATCI field test protocols in extreme heat conditions. The hot-chamber evaluation demonstrated a $25.5 \%$ cooling energy reduction with the thermal load reduction system from the baseline vehicle. This energy reduction corresponded to a $21.8 \%$ improvement in fuel economy during the test cycle. The savings are summarized in Table 3.

The NREL national-level A/C fuel use analysis process [3] is currently being converted to handle EVs by including cabin heating and an electrical A/C compressor. The new national-level $\mathrm{EV}$ range analysis process will be applied to the baseline and thermal load reduction Sonata PHEVs to determine the national-level EV range improvement.

Overall, the project provided technical data and multidisciplinary evaluation methods/analysis tools that can be used by the automobile industry to assess the system-level thermal impacts of vehicle design to minimize the impact of climate control on EDV range. An additional benefit of the thermal load reduction system is improved time to comfort. This project demonstrated a system that achieves reduced climate control loads and increased driving range in hot and cold environments. The increased range raises the probability of EDVs to meet everyday drive needs of consumers and accelerates the mass-market acceptance of EDVs.

\section{References}

1. Rask, E., "Argonne National Laboratory Advanced Powertrain Research Facility Data," presented at the Vehicle Systems Analysis Technical Team (VSATT) Meeting, 2 Apr 2014.
2. Kreutzer, C., Rugh, J., and Tomerlin, J., “Thermal Load Reduction System Development in a Hyundai Sonata PHEV," SAE Technical Paper 2017-01-0186, 2017, doi:10.4271/201701-0186.

3. Rugh, J.P., Kreutzer, C., Kekelia, B., Lustbader, J. et al., "U.S. Light-Duty Vehicle Air Conditioning Fuel Use and the Impact of Four Solar/Thermal Control Technologies," 17TMSS-0056, Presented at SAE 2017 Thermal Management Systems Symposium, Plymouth, MI, Oct 2017.

\section{Contact Information}

\section{John P. Rugh}

National Renewable Energy Laboratory

Transportation and Hydrogen Systems Center

john.rugh@nrel.gov

303-275-4413

\section{Acknowledgments}

This work was supported by the U.S. Department of Energy under Contract No. DE-AC36-08GO28308 with the National Renewable Energy Laboratory. Funding provided by the Vehicle Technologies Office, Office of Energy Efficiency and Renewable Energy, U.S. Department of Energy, for sponsoring this research. The authors would like to thank program managers David Anderson and Lee Slezak in the Vehicle Technologies Office.

The U.S. Government retains and the publisher, by accepting the article for publication, acknowledges that the U.S. Government retains a nonexclusive, paid-up, irrevocable, worldwide license to publish or reproduce the published form of this work, or allow others to do so, for U.S. Government purposes.

\section{Definitions/Abbreviations}

A/C - air conditioning

EDV - electric-drive vehicle

EV - electric vehicle

HATCI - Hyundai America Technical Center, Inc.

HVAC - heating, ventilating and air conditioning

NREL - National Renewable Energy Laboratory

PHEV - plug-in hybrid electric vehicle

SOC - state of charge

This is the work of a Government and is not subject to copyright protection. Foreign copyrights may apply. The Government under which this paper was written assumes no liability or responsibility for the contents of this paper or the use of this paper, nor is it endorsing any manufacturers, products, or services cited herein and any trade name that may appear in the paper has been included only because it is essential to the contents of the paper. 